\title{
MEASURING STUDENTS' INTEREST TOWARDS ENGINEERING IN TECHNICAL SCHOOL: A CASE STUDY
}

\author{
Nurul Asyikin Mohamed Radzi (D), Suhaila Sulaiman (iD) \\ Universiti Tenaga Nasional (Malaysia) \\ asyikin@uniten.edu.my,subailas@uniten.edu.my
}

Received December 2017

Accepted February 2018

\begin{abstract}
Estimating from the steady declining rate of engineering students in Malaysia, the country is predicted to be short of 236,000 engineers and technical personnel to achieve its 2020 Mission. Hence, it has built the first technical MARA Junior Science College that introduced engineering to lower secondary students. However, there is yet a study on whether or not it helps the students to increase their interests in engineering. Therefore, in this paper, a survey has been conducted to first and foremost investigate the technical students' interests in engineering as well as finding out the reasoning from those who are not interested in engineering. After that, a half day engineering program is introduced with a measurement on the interest in engineering before and after the intervention is held. Finally, the survey studies which field of engineering the students are most interested in. The results show that, before the program is introduced, only $8.47 \%$ of the technical students have shown high interests in engineering field with only $7.5 \%$ female students are interested in engineering compared to $18.42 \%$ for male students. After the program is introduced, as high as 33.05\% students rated their interest in engineering field as 'most interested', with $39.47 \%$ in male students and 30\% in female students. It proves that an engineering event is crucial in increasing students' interests in engineering. It also concludes that Electrical Engineering is the most favourite field of engineering with percentage score of 38.98\%, while Electrical Power being the least.
\end{abstract}

Keywords - Engineering, Interest, Intervention, Technical school.

\section{Introduction}

Recognized by the International Monetary Fund (IMF) as an emerging and developing country, Malaysia has a growing gross domestic product of an average $6.5 \%$ per annum for the past 50 years. Although initially Malaysia relies heavily on raw natural resources, during these pasts few years it has started to expand as one of the leading exporters of natural gases and electronics and electrical appliances sectors. Besides, with the rapid constructions and infrastructure developments, it is estimated by The National Council for Scientific Research and Development that 493,830 engineers will be needed in Malaysia by 2020 (Christina, 2016).

In order to achieve this, the first National Science and Technology Enrolment Policy of 60:40 is implemented in 1970 which states that $60 \%$ of students must be enrolled in science, whereas the remaining $40 \%$ in arts (Angelina, 2017). This 60:40 policy is further supported by The Malaysia Education Blueprint 2013-2025 that aims at improving the teaching and learning process of science and mathematics related subject to increase the number of students in science streams, including engineering (Ministry of Education Malaysia, 2013).

However, estimating from the current trend, Ministry of Science, Technology and Innovation predicted that Malaysia will still be short of 236,000 technical personnel to achieve its 2020 Mission (Ministry of Education Malaysia, 2013). This is due the steady declining interest in engineering courses not only in Malaysia, but also 
worldwide over the last five to ten years. This trend is especially significant for universities in Hong Kong, South Africa and even India that recorded a steady decline of 100,000 engineering students in the past two years.

In order to implement and maintain the development projects in Malaysia, it is very crucial to attract more engineering students as otherwise the progress of the country will be delayed. In Malaysia, students are able to choose the stream or field of their studies as early as when they are in upper secondary. While the government is expecting $60 \%$ of students to enroll in science stream, the statistics in 2014 shows that only $21 \%$ of the upper secondary students are choosing science subjects. This worrying trend will further cause a shortage of science graduates in coming years, especially in engineering.

Hence, in addition, Malaysia has built 69 science secondary schools and 51 MARA Junior Science Colleges up to date. In recent years, Malaysia even hosted the first technical MARA Junior Science College that introduced engineering to lower secondary students, as early as 13 years of age. However, there is yet a study on whether or not it helps the students to increase their interests in engineering, or they would be inclined to change their field later on in upper secondary.

Therefore, in this paper, a study of students' interests in engineering field has been done, specifically in technical school to evaluate their interests after three years that they have been exposed with engineering syllabus, facilities and environment. An engineering program will also be introduced with the aim of studying the interests in students before and after the program, whether it helps in increasing the students' interests and at what level. Furthermore, an evaluation on which field of engineering that the students are more inclined to pursue their studies in the future will be done. Finally, all these studies will take into account on the genders so that the right control actions can be done in the future.

To the best of our knowledge, this is the first time such study is done in the country and the results are expected to provide one of the solutions to help increase back the number of engineering students in Malaysia.

\section{Literature Review}

Up to date, although with the declining rate of engineering students worldwide, studies on the interests of students towards engineering field is still limited especially in Malaysia. (Ing, Aschbacher \& Tsai, 2014) studies on gender differences in engineering and science career preferences in America. The initial studies towards seventh, eight, and ninth grade students show that male students have more tendency to express interest in engineering career by $45 \%$. However, over time, from seventh through ninth grade, female students have becoming less consistent in their engineering career interests. It has also confirmed that childhood interests in engineering is related to their interest in engineering career for both genders. It further concludes that both females have less interest in innovation and technology. With these findings, we have zoomed in our research on 15 years old students as they have better views on what their career path would be in the future.

In Meng, Idris and $\mathrm{Eu}(2014)$ the focus of the study is to observe the views of secondary students on the assessments in STEM related subjects. The study is done in three different categories of secondary schools in Peninsular Malaysia; namely Daily High-Performing, Full Boarding High-Performing, and Daily Normal. The conclusion achieved from the study is that, significant difference can be observed in overall perceptions of assessments in STEM related subjects in terms of school category. However, the difference in overall perceptions is not significant for STEM related subjects in terms gender. With these findings, we have further focused our research to Full Boarding High-Performing school category as we would like to further gauge on the students' interests in engineering, considering the overall perceptions of these students in STEM related subject is better.

In (Hernandez, Bodin, Elliott, Ibrahim, Rambo-Hernandez, Chen et al., 2014), a complex classroom intervention has been developed to measure the perceptions of students on the STEM content. The study is done in five Colorado high schools, towards students enrolled in STEM classes. A pretest was given 
prior to the intervention, and approximately 24 weeks after the intervention began, the students were given posttest. The results indicate that the intervention has higher success rate in students with low perceptions of STEM connections. Hence, we would like to study the effects of intervention in lower secondary students in Malaysia, whether it would also help increase the interests of students in engineering field.

Cheryan, Master and Meltzoff (2015) study on the stereotyping of computer science and engineering in modern American culture as a field dominated by male. The researcher hypothesized on the students' stereotypes about the kind of people, the work involved, and the values of the field, which when combined together caused female students to have less interest in the streams. The paper concludes that by altering the stereotypes has significantly increase the female students' interests in computer science and engineering field. Due to this reason, the studies on engineering interests based on genders will also be done. Detailed explanation on the methodology of the research is discussed in Section 3.

\section{Methodology}

\subsection{Sample}

Survey respondents were recruited in 15 years old students of MARA Junior Science College (MRSM) Bentong in Pahang, Malaysia. Introduced under the initiative of Rancangan Malaysia Ke-11 (RMK-11), MRSM Bentong is the first technical MRSM in Malaysia that introduces technical learning, robotics and engineering science module as early as 13 years old. It is also equipped with sophisticated laboratory equipment with the aim of keeping the excellent students' interests in engineering field so that they will choose technical majoring when they are 16 years old or later on in university. 118 students have participated in the survey; $32 \%$ of the students are male students whereas $68 \%$ are female students.

\subsection{Measures}

The method used to investigate fifteen years old students' perceptions of assessments in STEM related subjects consisted of a questionnaire which had three sections, namely Section A, B and C as in Figure 1. Section A is to investigate their interests in engineering as well as finding out the reasoning from those who are not interested in engineering. Section B is to measure the interest in engineering before and after an intervention is introduced. Whereas Section $C$ is to study which field of engineering they are interested in. The item in Section B had a five-point Likert scale response options. The students' responses to each item received weighted values from 1 (least interested) to 5 (most interested).

\subsection{Intervention}

A number of methods have been introduced as an intervention towards students to increase their interests and understanding in engineering. Among them is gamification (Sánchez-Carmona, Robles \& Pons, 2017) and simulation (Chen, We, \& Li, 2016). In this study, the intervention introduced is a half day engineering program that started with talks, discussions, quizzes, demonstrations, and games. Two male and one female facilitators from different engineering background have been invited to anchor the event. A dedicated Question and Answer sessions has been organized to cater to the students' questions regarding engineering both openly and one-to-one. Videos on the current and future technology have also been introduced to give them exposure on what engineering is all about.

\section{Results}

\subsection{Section A: Interests in Engineering Before Intervention}

Table 1 shows initial interests of students in engineering before the intervention. Although it is easy to hypothesized that the students have vast interests in engineering considering the sample of the study is in a technical school that have been exposed to engineering syllabus and lab for approximately three years, the results of the survey have proven otherwise. Only $8.47 \%$ of the technical students have shown high interests in engineering field whereas $24.58 \%$ students have the least interests in the field. Observing the 
gender interests, as expected, only $7.5 \%$ female students are interested in engineering compared to $18.42 \%$ for male students.

The significance behind their lack of interests in engineering varies from misconception of engineering field to the fact that they do not think being an engineer is able to help people, but $59.26 \%$ of those who have less interests in engineering stated that they are not interested in engineering due to the difficulty level and that they are not confident that they are able to cope with the study.

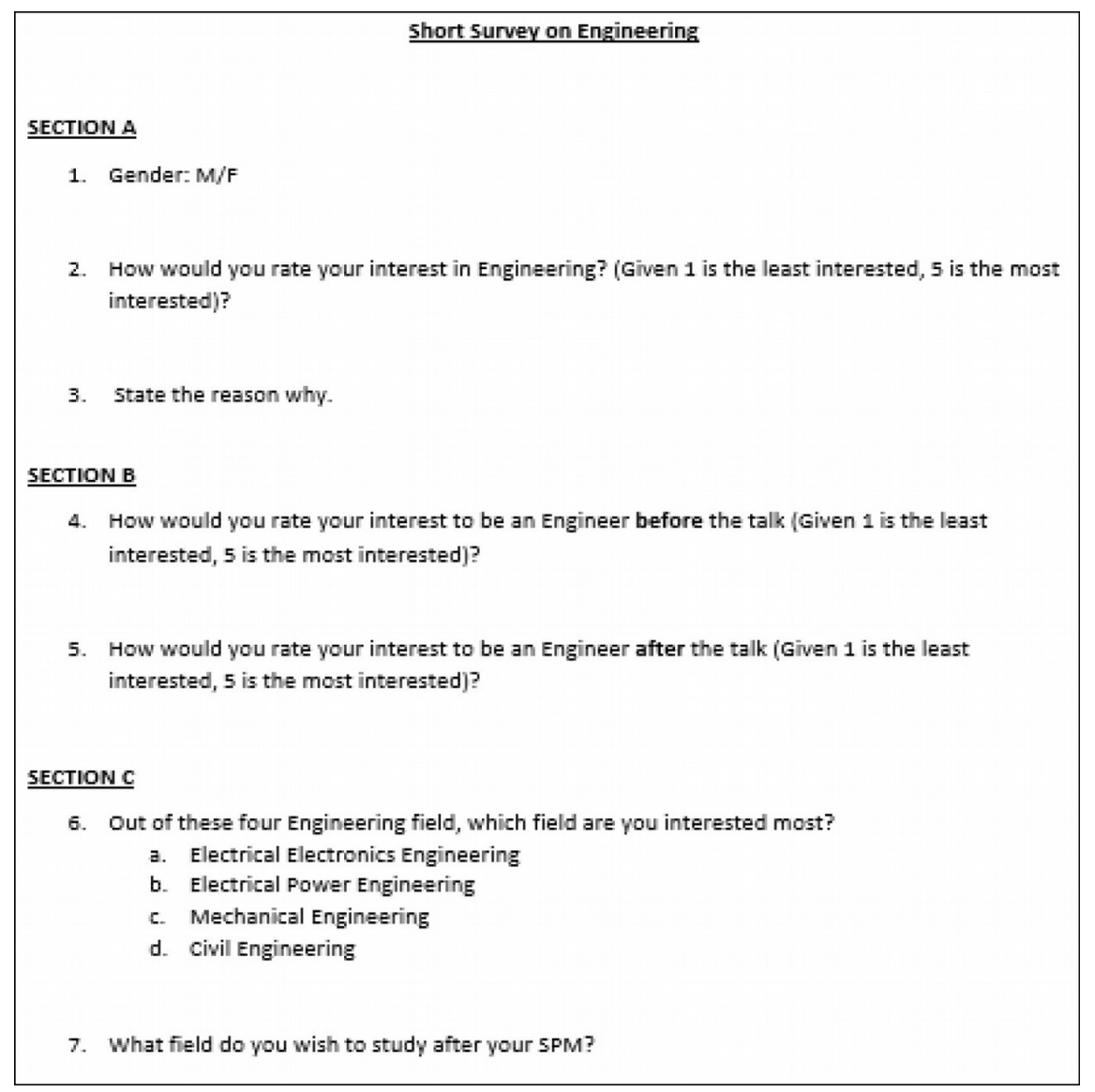

Figure 1. Survey questions

\begin{tabular}{|l|r|r|r|r|r|}
\hline Gender/Interest & $\mathbf{1}$ (least interested) & $\mathbf{2}$ & $\mathbf{3}$ & $\mathbf{4}$ & $\mathbf{5}$ (most interested) \\
\hline Male & $5.26 \%$ & $10.53 \%$ & $52.63 \%$ & $18.42 \%$ & $13.16 \%$ \\
\hline Female & $33.75 \%$ & $18.75 \%$ & $33.75 \%$ & $7.50 \%$ & $6.25 \%$ \\
\hline Overall & $24.58 \%$ & $16.10 \%$ & $39.83 \%$ & $11.02 \%$ & $8.47 \%$ \\
\hline
\end{tabular}

Table 1. Initial Interests in Engineering

\subsection{Section B: Measuring the Interests in Engineering Before and After the Program}

Figure 2 shows a pie chart on students' interest in engineering before and after the program has been conducted. It shows a remarkable figure in which the engineering program has drawn more interests for the students to pursue in engineering field as high as $77.97 \%$. Whereas, $21.19 \%$ remains unchanged with their decision and $0.85 \%$ has becoming less interested with engineering field after the talk. Further breakdown of the results in terms of gender can be seen in Table 2 where female students have becoming more interested to pursue in engineering study, $17.96 \%$ higher compared to male students after the program. 


\begin{tabular}{|l|r|r|r|}
\hline Gender/Interest & Less interested & Unchanged & \multicolumn{1}{c|}{ More interested } \\
\hline Male & $0.00 \%$ & $34.21 \%$ & $65.79 \%$ \\
\hline Female & $1.25 \%$ & $15 \%$ & $83.75 \%$ \\
\hline Overall & $0.85 \%$ & $21.19 \%$ & $77.97 \%$ \\
\hline
\end{tabular}

Table 2. Students' Interests in Engineering Before and After the Program According to Gender

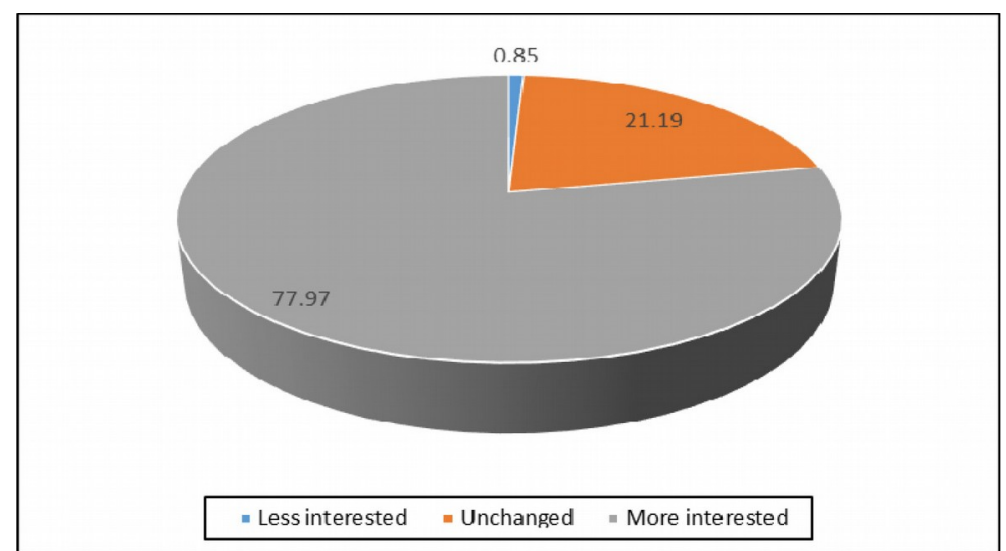

Figure 2. Students' Interests in Engineering Before and After the Program

\begin{tabular}{|l|r|r|r|r|r|r|}
\hline Gender/Interest & \multicolumn{1}{|c|}{$\mathbf{2 5 \%}$} & $\mathbf{0 \%}$ (unchanged) & \multicolumn{1}{c|}{$\mathbf{2 5 \%}$} & \multicolumn{1}{c|}{$\mathbf{5 0} \%$} & $\mathbf{7 5 \%}$ & $\mathbf{1 0 0} \%$ \\
\hline Male & $0.00 \%$ & $34.21 \%$ & $47.37 \%$ & $15.79 \%$ & $0.00 \%$ & $2.63 \%$ \\
\hline Female & $1.25 \%$ & $15 \%$ & $31.25 \%$ & $32.5 \%$ & $16.25 \%$ & $3.75 \%$ \\
\hline Overall & $0.85 \%$ & $21.19 \%$ & 36.445 & $27.12 \%$ & $11.02 \%$ & $3.39 \%$ \\
\hline
\end{tabular}

Table 3. Percentage Increment on Interest Level of Students in Engineering After the Program According to Gender

\begin{tabular}{|l|c|c|c|c|c|}
\hline Gender/Interest & $\mathbf{1}$ (least interested) & $\mathbf{2}$ & $\mathbf{3}$ & $\mathbf{4}$ & $\mathbf{5}$ (most interested) \\
\hline Male & $0.00 \%$ & $0.00 \%$ & $23.68 \%$ & $36.84 \%$ & $39.47 \%$ \\
\hline Female & $2.5 \%$ & $6.25 \%$ & $17.5 \%$ & $43.75 \%$ & $30 \%$ \\
\hline Overall & $1.69 \%$ & $4.24 \%$ & $19.49 \%$ & $41.53 \%$ & $33.05 \%$ \\
\hline
\end{tabular}

Table 4. Interests in Engineering After the Program

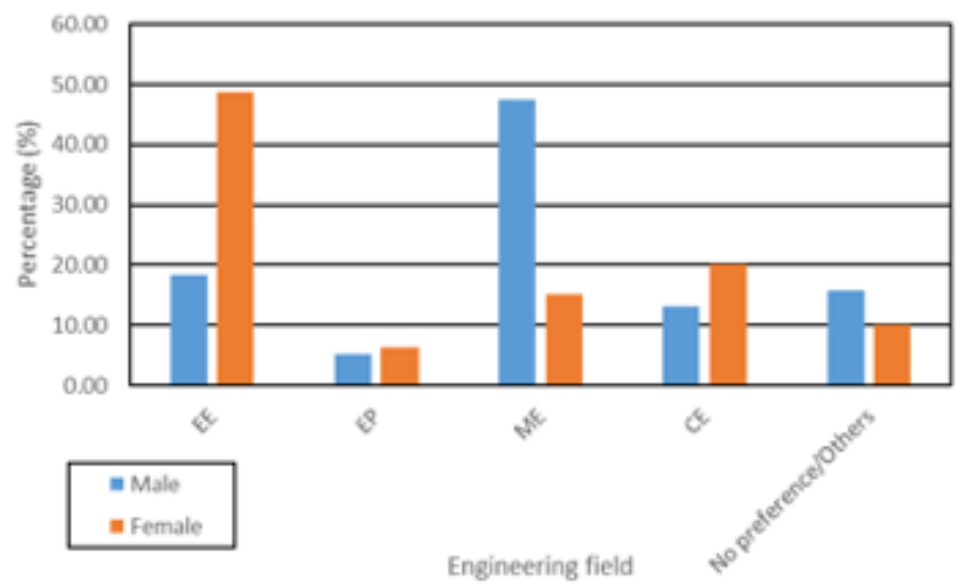

Figure 3. Field of engineering preferred by students 
In Table 3, we further tabulated the increment on interest level of the students towards engineering field after the half day event was organized. 3.75\% female students show 100\% increment in their interest towards engineering field after the program, marking $1.12 \%$ higher than the male students.

Table 4 shows the interests of engineering in the students after the program. As high as 33.05\% students rated their interest in engineering field as 'most interested', with $39.47 \%$ in male students and $30 \%$ in female students. This shows an overall improvement of $24.58 \%$ compared to 'most interested' field before the program; being $26.32 \%$ improvements in male students and $23.75 \%$ in female students.

\subsection{Section C: Engineering Field of Interest}

The study on engineering field of interest towards the students show that Electrical and Electronics Engineering (EE) is the most favourite field of all with percentage score of $38.98 \%$. This is followed by Mechanical Engineering (ME) at 25.42\%, Civil Engineering (CE) at 17.8\% and finally Electrical Power (EP) at $5.93 \%$. A total of $11.86 \%$ has no preference or still undecided on which Engineering field they are interested in.

Figure 3 shows the breakdown of the results according to gender, which shows that more male students are interested in ME. With the score of $47.37 \%$, the number of male students that are interested in ME exceeds female students by $32.37 \%$. On the other hand, more female students are interested in EE with a score of $48.75 \%$. It exceeds the number of male students by $30.33 \%$. In both genders however, there are less number of students interested in EP; scoring 5.26\% for male students and $6.25 \%$ in female students.

\section{Conclusion}

The first National Science and Technology Enrolment Policy of 60:40 is implemented in 1970 which states that $60 \%$ of students must be enrolled in science, whereas the remaining $40 \%$ in arts. However, the statistics in 2014 shows that only $21 \%$ of the upper secondary students are choosing science subjects. Hence, Malaysia has built the first technical MARA Junior Science College that introduced engineering to lower secondary students, as early as 13 years of age. However, there is yet a study on whether or not it helps the students to increase their interests in engineering. Therefore, in this paper, a survey has been conducted to first and foremost investigate the technical students' interests in engineering as well as finding out the reasoning from those who are not interested in engineering. After that, a half day engineering program is introduced with a measurement on the interest in engineering before and after the intervention is held. Finally, the survey studies which field of engineering the students are most interested in. The results show that, before the program is introduced, only $8.47 \%$ of the technical students have shown high interests in engineering field with only $7.5 \%$ female students are interested in engineering compared to $18.42 \%$ for male students. After the program is introduced, as high as $33.05 \%$ students rated their interest in engineering field as 'most interested', with 39.47\% in male students and 30\% in female students. It proves that an engineering event is crucial in keeping and increasing students' interests in engineering. This paper further concludes that Electrical Electronics Engineering is the most favourite field of engineering with percentage score of $38.98 \%$, while Electrical Power being the least.

\section{Declaration of Conflicting Interests}

The authors declared no potential conflicts of interest with respect to the research, authorship, and/or publication of this article.

\section{Funding}

The authors received no financial support for the research, authorship, and/or publication of this article.

\section{References}

Angelina, A. (2017). STEM, a priority for Malaysia. The Star Online. Available at: https://www.thestar.com.my/news/education/2017/03/12/stem-a-priority-for-malaysia/ 
Chen, B., Wei, L., \& Li, H. (2016). Teaching complicated conceptual knowledge with simulation videos in foundational electrical engineering courses. Journal of Technology and Science Education, 6(3).

https://doi.org/10.3926/jotse.174

Cheryan, S., Master, A., \& Meltzoff, A.N. (2015). Cultural stereotypes as gatekeepers: increasing girls' interest in computer science and engineering by diversifying stereotypes. Frontiers in Psychology, 6. https://doi.org/10.3389/fpsyg.2015.00049

Christina, C. (2016, February 28). Nation builders wanted. The Star Online. Available at: https://www.thestar.com.my/news/nation/2016/02/28/nation-builders-wanted-malaysias-dream-of-becoming-ahighincome-nation-by-2020-could-crumble-if-we-d/

Hernandez, P.R., Bodin, R., Elliott, J.W., Ibrahim, B., Rambo-Hernandez, K.E., Chen, T.W., et al. (2014). Connecting the STEM dots: measuring the effect of an integrated engineering design intervention. International Journal of Technology and Design Education, 24(1), 107-120. https://doi.org/10.1007/s10798-013$9241-0$

Ing, M., Aschbacher, P.R., \& Tsai, S.M. (2014). Gender differences in the consistency of middle school students' interest in engineering and science careers. Journal of Pre-College Engineering Education Research (J-PEER), 4(2), 2. https://doi.org/10.7771/2157-9288.1090

Meng, C.C., Idris, N., \& Eu, L.K. (2014). Secondary Students' Perceptions of Assessments in Science, Technology, Engineering, and Mathematics (STEM). Eurasia Journal of Mathematics, Science \& Technology Education, 10(3).

Ministry of Education Malaysia (2013). Malaysia Education Blueprint 2013-202. Available at: https://www.moe.gov.my/index.php/en/dasar/pelan-pembangunan-pendidikan-malavsia-2013-2025 (Accessed: December 2017).

Sánchez-Carmona, A., Robles, S., \& Pons, J. (2017). A gamification experience to improve engineering students' performance through motivation. Journal of Technology and Science Education, 7(2), 150-161. https://doi.org/10.3926/jotse.246

Published by OmniaScience (www.omniascience.com)

Journal of Technology and Science Education, 2018 (www.jotse.org)

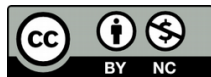

Article's contents are provided on an Attribution-Non Commercial 4.0 Creative commons International License.

Readers are allowed to copy, distribute and communicate article's contents, provided the author's and JOTSE journal's names are included. It must not be used for commercial purposes. To see the complete licence contents, please visit https://creativecommons.org/licenses/by-nc/4.0/. 